H. E. Larsson · K. Lynch · B. Lernmark • A. Nilsson - G. Hansson •

P. Almgren · Å. Lernmark - S-A. Ivarsson - DiPiS Study Group

\title{
Diabetes-associated HLA genotypes affect birthweight in the general population
}

Received: 6 December 2004 / Accepted: 20 March 2005 / Published online: 1 July 2005

(C) Springer-Verlag 2005

\begin{abstract}
Aims/hypothesis: The aim of our study was to test the hypothesis that HLA genotypes conferring risk of diabetes, cord blood autoantibodies, or both are associated with increased birthweight. Methods: HLA genotypes were determined in dried blood spots of cord blood from a total of 16,709 children born to healthy mothers in the Diabetes Prediction in Skåne (DiPiS) study, a population-based observational clinical investigation of newborn children. Children born to mothers with diabetes or gestational diabetes were excluded. Autoantibodies to glutamic acid decarboxylase (GAD65Ab) and insulinoma-associated protein 2 were determined in standard radioligand binding assays. Birthweight was adjusted for gestational age and divided into quartiles. The upper quartile was defined as high relative birthweight ( $\mathrm{HrBW})$ and the lower quartile as low relative birthweight (LrBW). Results: Genotypes conferring risk of type 1 diabetes were strongly associated with relative birthweight $(\mathrm{rBW})(p=0.01)$. The high-risk HLA-DQ2/8, DQ8/0604 and DQ8/X genotypes were associated with $\mathrm{HrBW}$ (odds ratio $[\mathrm{OR}][95 \% \mathrm{CI}]=1.20$ [1.08-1.33], $p=0.0006)$. The HLA-DQB1*0603 allele, which is negatively associated with type 1 diabetes, was also associated with $\mathrm{HrBW}(p=0.025)$, confirming a previous report on DQB1*0603-linked HLA-DR13. GAD65Ab were negatively associated with $\mathrm{HrBW}(\mathrm{OR}[95 \% \mathrm{CI}]=$ 0.72 [0.56-0.93], $p=0.01$ ). Regression analysis showed that the HLA-associated increase in $\mathrm{rBW}$ was independent of confounding factors. Conclusions/interpretation: HLA genotypes may be associated with intrauterine growth independent of type 1 diabetes risk. The epidemiological observation that high birthweight is a risk factor for type 1
\end{abstract}

\footnotetext{
H. E. Larsson · K. Lynch · B. Lernmark · A. Nilsson Lund University,

Malmö, Sweden

H. E. Larsson $(\bowtie)$

Department of Clinical Sciences-Pediatrics,

University Hospital MAS,

20502 Malmö, Sweden

e-mail: helena.larsson@med.lu.se
}

G. Hansson · P. Almgren - A. Lernmark - S.-A. Ivarsson Department of Clinical Sciences, University Hospital MAS, diabetes could possibly result from a moderating effect on intrauterine growth of HLA genotypes conferring a high risk of diabetes.

Keywords Birthweight - Diabetes mellitus - GAD65 autoantibodies · HLA · HLA-DQ2 - HLA-DQ8 - IA-2 autoantibodies $\cdot$ Insulin-dependent diabetes $\cdot$ Screening Type 1 diabetes

Abbreviations BW: birthweight - DBS: dried blood spots - DiPiS: Diabetes Prediction in Skåne - GAD65: glutamic acid decarboxylase - GAD65Ab: glutamic acid decarboxylase autoantibodies $\cdot \mathrm{HrBW}$ : high relative birthweight - IA-2: insulinoma-associated protein 2 . IA-2Ab: insulinoma-associated protein 2 autoantibodies . LGA: large for gestational age $\cdot$ LrBW: low relative birthweight - OR: odds ratio - $\mathrm{rBW}$ : relative birthweight . SGA: small for gestational age

\section{Introduction}

Type 1 diabetes or insulin-dependent diabetes mellitus, is a chronic disease caused by an autoimmune destruction of the pancreatic islet beta cells. The incidence of type $1 \mathrm{di}-$ abetes before 15 years of age is increasing [1,2], especially for children diagnosed at an early age [3-7]. HLA susceptibility genes are strongly associated with type 1 diabetes [8-11]. Still the concordance rate for identical twins to develop disease is below $50 \%[12,13]$, which indicates that environmental factors are of importance.

It has been speculated that wealth-based overnutrition could be of importance for the current increase in type 1 diabetes incidence [14]. Children born large for gestational age (LGA) had a higher risk of type 1 diabetes later in childhood [15]. In one study the incidence of type 1 diabetes was found to increase almost linearly with birthweight (BW) [16].

HLA-DQ on chromosome 6 is the major genetic factor for type 1 diabetes. About $60 \%$ of the genetic susceptibility is explained by HLA $[8,17]$. HLA-DQB $1 * 0302-\mathrm{A} 1 * 0301$ 
(DQ8) and HLA-DQB1*0201-A1*0501 (DQ2) confer the highest risk for type 1 diabetes, especially when both are present in the genotype. Almost $90 \%$ of people with type 1 diabetes have at least one of these haplotypes [9].

The autoimmune process destroying the beta cells is thought to occur at different rates. The pathogenesis seems to be marked by autoantibodies against glutamic acid decarboxylase (GAD65Ab) [18], insulinoma-associated protein 2 (IA-2Ab) $[19,20]$ and insulin [21], alone or in combination. Up to $90 \%$ of children with newly diagnosed type 1 diabetes have at least one of these autoantibodies at diagnosis and $85 \%$ of children developing diabetes do not have a first-degree relative with the disease. Islet autoantibodies have been found retrospectively in cord blood from some children who later developed type 1 diabetes [22], and it was therefore speculated that intrauterine factors might contribute to type 1 diabetes risk.

LGA and other altered growth rates appear to be associated with type 1 diabetes risk [15, 16, 23-26]. It is not clear whether islet autoantibodies are associated with LGA or growth, or whether the relationship between high BW and type 1 diabetes is a result of the same genes being associated with both increased risk for type 1 diabetes and high BW. It has recently been reported that there is an association between HLA-DR13 and mean BW [27]. We have extended this study to a large cohort of the general population to test the hypothesis that HLA genotypes that define type 1 diabetes risk, cord blood GAD65Ab and IA$2 \mathrm{Ab}$, or both, are associated with BW. Since diabetes in the mother compromises fetal growth, we excluded all children born to mothers with diabetes or gestational dia- betes. Hence, in contrast to previous investigations on the relationship between type 1 diabetes and BW $[15,16]$, we examined HLA genotypes in relation to BW, with particular emphasis on genotypes conferring risk of type 1 diabetes.

\section{Materials and methods}

Population The children in this study were included in DiPiS (Diabetes Prediction in Skåne), a prospective, population-based study in Skåne, the most southern province of Sweden. The aim of DiPiS is to determine the positive predictive value for type 1 diabetes of genetic risk combined with islet cell autoantibody markers. The aim of DiPiS is also to identify factors before and after pregnancy that may trigger type 1 diabetes.

Blood samples were obtained from all mothers at delivery. Cord blood DNA was genotyped for HLA and for autoantibodies to GAD65 and IA-2. The parents fill in consent and questionnaire forms when the child is 2 months of age. The forms include family history of diabetes, birthweight and gestational age.

The Lund University Ethics Committee approved the DiPiS study.

HLA genotyping HLA was analysed on dried blood spots (DBS) on filters as described [28, 29]. Filter samples (3 $\mathrm{mm}$ in diameter) of DBS were punched into 96-well PCR plates. HLA-DQB1 alleles were amplified with sequencespecific primers. The product was transferred to DELFIA streptavidin-coated microtitration plates (Perkin Elmer
Fig. 1 Children born in the region of Skåne in Sweden between September 2000 and December 2003, and the frequency of participation and exclusion in the DiPiS study

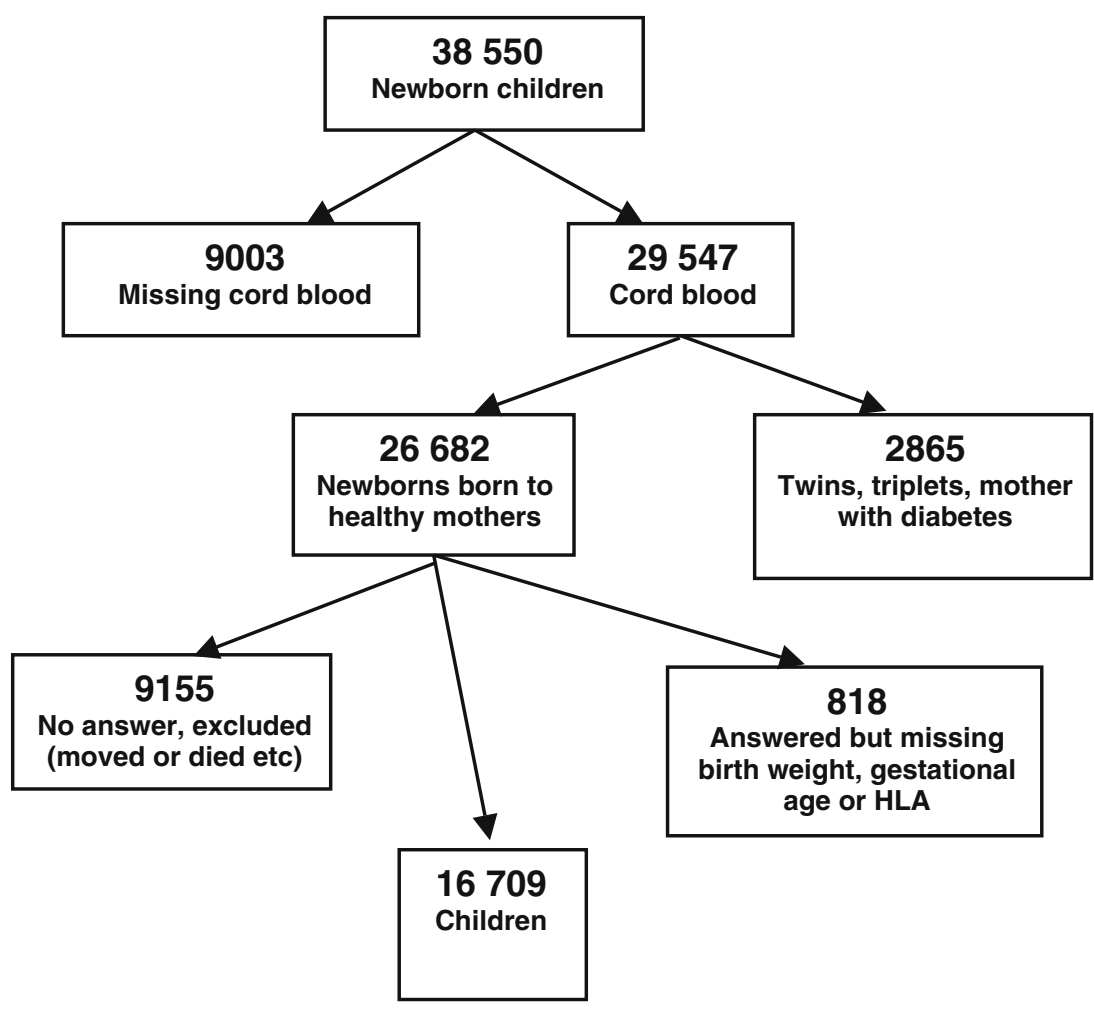


Table 1 Factors in mother and newborn associated with participation in the study

\begin{tabular}{llc}
\hline Factor & OR $(95 \% \mathrm{CI})^{\mathrm{a}}$ & $p$ value \\
\hline Increasing maternal age (years) & $1.04(1.04-1.05)$ & $<0.001$ \\
Increasing gestational age (weeks) & $1.04(1.03-1.06)$ & $<0.001$ \\
Sex of child: girl & $0.99(0.94-1.05)$ & 0.75 \\
GAD65Ab or IA-2Ab & $1.07(0.91-1.25)$ & 0.44 \\
HLA-DQB1 T1DM risk & & \\
Moderate to high risk of T1DM & $1.06(0.99-1.13)$ & 0.09 \\
\hline
\end{tabular}

Children included in the study are compared with children with missing birthweight born of healthy mothers

Odds ratios of participation were calculated in a multiple logistic regression

TIDM type 1 diabetes mellitus

${ }^{a}$ Odds ratio $>1$ indicates more likely to participate

Life Sciences, Boston, MA, USA) and diluted with DELFIA hybridisation buffer. After incubation and denaturation the single-stranded DNA was hybridised with two sets of probes (Perkin Elmer Life Sciences). The first set contains Eu-DQB1*0602/3, Sm-DQB1*0603/4 and Tb Control. The second one contains Eu-DQB1*0302, Sm$\mathrm{DQB} 1 * 0301$ and Tb-DQB1*02. After washing and adding the DELFIA enhancement solution, the $\mathrm{Eu}$ and $\mathrm{Sm}$ fluorescence was counted in a Victor2 MultiLabel Counter (Perkin Elmer Life Sciences). The Tb signal-to-noise ratio was calculated with MultiCalc (Perkin Elmer Life Sciences). The samples positive for DQB $1 * 02$ were further analysed for DQA $1 * 0201$ and 05 alleles to separate DR3 from subjects with DR7. HLA-DQA1 typing was performed with the same technique as for DQB1 typing with some modifications: using streptavidin-coated plates, dilution with DELFIA hybridisation buffer (Perkin Elmer Life Sciences) and the use of Sm-DQA ${ }^{*} 05$ and TbDQA $1 * 0201$ probes.

The HLA genotypes were divided into seven risk groups for type 1 diabetes (Table 4): (1) very high risk having DQB $1 * 0201-\mathrm{A} 1 * 0501$ and $\mathrm{DQB} 1 * 0302-\mathrm{A} 1 * 0301$; (2) high risk having DQB1*0302-A1*0301 but not DQB1 *0201-A1*0501; (3) moderate risk having DQB $1 * 0201$ DQA $1 * 0501$ but not DQB $1 * 0302-A 1 * 0301$; (4) neutral HLA; (5) low-risk HLA; (6) very low risk; and (7) no-risk HLA.

GAD65 and IA-2 autoantibodies Autoantibodies (Ab) to GAD65 or IA-2 were determined in a first combined screen, where eluates from DBS were incubated with labelled antigen, antibody-bound labelled antigen separated from free by Sepharose-Protein A (Amersham Biosciences, Uppsala, Sweden) and the radioactivity counted in a Beta Plate Reader (Perkin Elmer Life Sciences) as described elsewhere [30]. The combined screen, referred to as $\mathrm{COMB}$, compared a positive reference with two negative samples to determine a cut-off level that would require the sample to be analysed for both GAD65 Ab and IA-2Ab in separate assays. Levels above COMB of $1.0 \mathrm{U} / \mathrm{ml}$ were considered high, and reassayed individually for GAD65Ab and IA-2Ab [31, 32]. GAD65Ab above $35 \mathrm{U} / \mathrm{ml}$ and IA- $2 \mathrm{Ab}$ above $6 \mathrm{U} / \mathrm{ml}$ were considered positive.

Statistical methods and datasets All questionnaires and forms from the DiPiS study and the results from HLA typing and antibody analyses were scanned into a database, BC/OS system, Biocomputing OS 2000 (Biocomputing Platforms Oy, Espoo, Finland).

In term newborns, relative BW (rBW) was calculated as $Z$-scores for each gestational week and sex by the following formula: $Z$-score $=(\mathrm{BW}-$ mean $[\mathrm{BW}]) / \mathrm{SD}[\mathrm{BW}]$.

Population means (SD) of BW were estimated internally using the study group. An ultrasound-corrected standardised mean BW for each gestational age and sex was also calculated for all newborns using two polynomial equation formulas. These formulas were polynomial regressions fitted to 759 ultrasonically estimated fetal weights in 86 uncomplicated pregnancies and are used as a base for the standard weights in Swedish maternity clinics [33, 34]. The SD was taken as $12 \%$ of the mean. LGA was defined as an ultrasound-corrected rBW above $2 \mathrm{SD}$, and small for gestational age (SGA) as an ultrasound-corrected rBW below 2 SD.

RBW was divided into quartiles, where children in the lower quartile were defined as having a low relative BW (LrBW) and children in the upper quartile a high relative BW (HrBW). The association between BW and HLA genotype risk groups was examined using chi-squared tests. Multiple logistic regression analysis was used to test whether diabetes-risk HLA genotypes were associated with HrBW or LrBW, after adjusting for sex of the child, maternal age and maternal smoking.

Twins and triplets were excluded from the analysis, as their BW is known to be lower than the standard. All children born to mothers with diabetes, including gestational diabetes, were also excluded from the study since their children are known to have a high BW.

Table 2 Characteristics of the children $(n=16,709)$ participating in the study

\begin{tabular}{lc}
\hline & $\begin{array}{l}\text { Number } \\
\text { of children }(\%)\end{array}$ \\
\hline Newborn & \\
Girl & $8,019(48.0)$ \\
Gestational age $<37$ weeks & $654(3.9)$ \\
Birthweight $<2,500 \mathrm{~g}$ & $364(2.2)$ \\
Birthweight $>4,500 \mathrm{~g}$ & $816(4.9)$ \\
Small for gestational age & $277(1.7)$ \\
$\quad$ (less than -2 SD) & $838(5.0)$ \\
Large for gestational age & \\
(more than +2 SD) & \\
Maternal factors & $1,522(9.1)$ \\
$<25$ years of age & $277(1.7)$ \\
$>40$ years of age & $1,597(9.6)$ \\
Smoked during pregnancy &
\end{tabular}


a

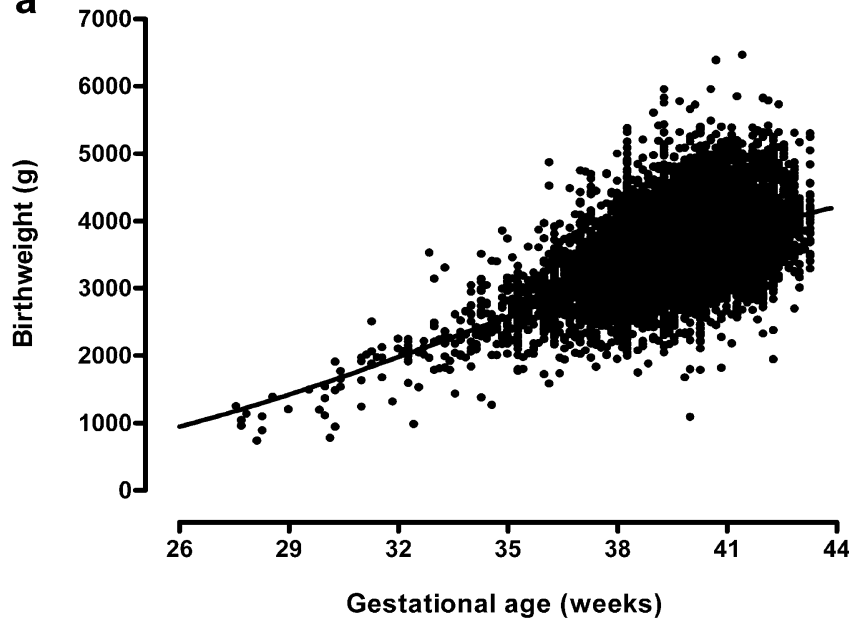

b
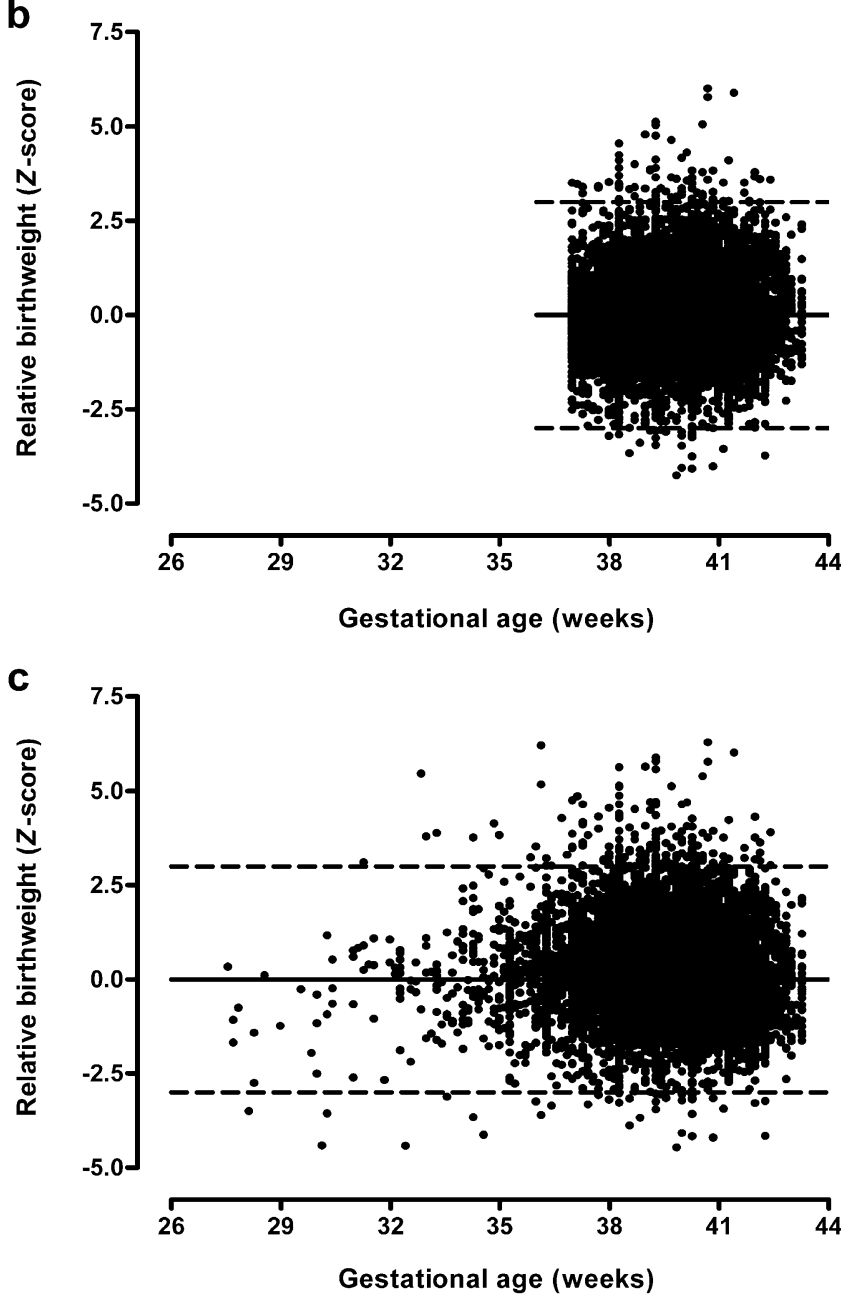

Results

Study group In all, 16,709 children who were included in the DiPiS study between September 2000 and December 2003 were fully analysed. During this period, approximately 38,550 children were born in the province of Skåne (Fig. 1). A total of 29,547 cord blood samples were
Fig. 2 Distribution (a) of birthweight in relation to gestational age in 16,709 children born to healthy mothers. The line represents the mean birthweight of boys and girls together as estimated by polynomial regression. b Distribution of relative birthweight using internal Z-scores (only including gestational ages 37 weeks or longer) in relation to gestational age in 16,055 children born to healthy mothers. The standard intrauterine growth curve (means \pm 3 $\mathrm{SD}$ ) is shown. c Distribution of relative birthweight using ultrasound $Z$-scores in relation to gestational age in 16,709 children born to healthy mothers. The standard intrauterine growth curve (means \pm 3 $\mathrm{SD})$ is shown

obtained at the five maternity clinics. After excluding twins, triplets and children born to mothers with diabetes $(n=2,865), 26682$ children remained. Of these, 17,527 of the parents completed a questionnaire and consented to the study when their child was 2 months old $[35,36]$. Reported BW from the questionnaire and gestational age recorded at birth were available on 16,709 children $(62.6 \%$ of the 26,682 eligible children). Since not all parents filled out the questionnaire, we next compared participating with non-participating children (Table 1), by using maternal and newborn information recorded at birth. Participation was higher with increasing age of the mother $(p<0.001)$ and with increasing gestational age $(p<0.001)$. There was no difference in frequency of diabetes-high-risk HLA or positive autoantibodies between the groups. Among the 16,709 newborn children, $51.3 \%$ were boys and $48.0 \%$ were girls (sex missing in $0.7 \%$ ) (Table 2).

Birthweight and relative birthweight The distribution of $\mathrm{BW}$, internal $Z$-scores and ultrasound-corrected BW $(\mathrm{rBW})$, which are shown in Fig. 2a, b and c, respectively, demonstrate that the mean ultrasound-corrected rBW was +0.2 $Z$-score, indicating this population to be slightly heavier than the Swedish standard fetal weights for gestational age. A total of $5.0 \%$ of the children were LGA while $1.7 \%$ were $\mathrm{SGA}$. The median (interquartile range) $\mathrm{BW}$ was $3,610 \mathrm{~g}$ $(3,275-3,950)$ and ultrasound-corrected rBW $0.15(-0.51$ to 0.85$) \mathrm{Z}$-score. Approximately $71 \%$ of children with HrBW had also a BW in the upper quartile and $69 \%$ of the children with LrBW had a BW in the lower quartile. Of the children with $\mathrm{HrBW}, 74(0.5 \%)$ had a low actual BW. These children were born preterm at 24-36 gestational weeks and were LGA (Fig. 2c). In the 16,055 term newborns, the quartiles of the ultrasound-corrected rBW and internal rBW matched in $87.6 \%$ of children. The remaining $12.4 \%$ differed randomly by no more than one quartile.

HLA-DQB1 genotypes HLA-DQB1 was first examined descriptively to determine and rank the DQB1 genotypes with the highest and lowest frequency of LrBW and HrBW (Table 3). Children with DQB1*0302, and either DQB1* 02, DQB1*0603, DQB1*0604 or diabetes-neutral DQX, had the highest frequency of $\mathrm{HrBW}$, while children with DQB $1 * 0302$, and either DQB $1 * 0301$ or DQB $1 * 0602$, the lowest frequency (Table 3). Children with diabetes-riskneutral DQX/DQX genotype also had a low frequency of HrBW. In contrast, LrBW was found highest in children with DQB1*0301/DQB1*0302. All children with DQB1* 
Table 3 Percent of different HLA-DQB1 genotypes $(95 \%$ CI) with low or high relative birthweight
$\mathrm{X}$ is not DQB1 02, 0301, 0302, 0602, 0603, 0604 but includes potential homozygosity

${ }^{a}$ Ranked from highest frequency to lowest frequency

${ }^{\mathrm{b}}$ Genotypes DQB1* 0603/0602, $0603 / 0604,0603 / \mathrm{X}$ or $0602 / 0604$

\begin{tabular}{|c|c|c|c|c|c|c|}
\hline \multirow{3}{*}{ Rank order ${ }^{\mathrm{a}}$} & \multicolumn{3}{|c|}{ Low relative birthweight } & \multicolumn{3}{|c|}{ High relative birthweight } \\
\hline & \multicolumn{2}{|c|}{ HLA DQB1 genotype } & \multirow{2}{*}{$\begin{array}{l}\text { Percent of genotype } \\
\%(95 \% \mathrm{CI})\end{array}$} & \multicolumn{2}{|c|}{ HLA DQB1 genotype } & \multirow{2}{*}{$\begin{array}{l}\text { Percent of genotype } \\
(95 \% \mathrm{CI})\end{array}$} \\
\hline & Haplo1 & Haplo2 & & Haplo1 & Haplo2 & \\
\hline 1 & 0301 & 0302 & $29.9(26.5-33.3)$ & 0603 & 0302 & $28.3(23.6-33.0)$ \\
\hline 2 & 0301 & 0604 & $27.3(21.9-32.7)$ & 0302 & $\mathrm{X}$ & $27.6(25.2-30.0)$ \\
\hline 3 & 02 & $X$ & $26.2(24.3-28.1)$ & 02 & 0302 & $27.5(24.6-30.4)$ \\
\hline 4 & 0301 & $\mathrm{X}$ & $26.0(23.9-28.1)$ & 0302 & 0604 & $27.0(20.8-33.2)$ \\
\hline 5 & 0302 & 0604 & $26.0(19.9-32.1)$ & 0603 & 02 & $26.6(22.7-30.5)$ \\
\hline 6 & 0301 & 02 & $25.6(23.0-28.2)$ & \multicolumn{2}{|c|}{$602 / 603 / 604^{\mathrm{b}}$} & $26.2(23.8-28.6)$ \\
\hline 7 & 0602 & 0301 & $25.6(22.6-28.6)$ & 0301 & 0604 & $25.4(20.1-30.7)$ \\
\hline 8 & $\mathrm{X}$ & $\mathrm{X}$ & $25.1(21.6-28.6)$ & 0604 & $\mathrm{X}$ & $25.1(20.8-29.4)$ \\
\hline 9 & 0602 & $\mathrm{X}$ & $24.7(22.5-26.9)$ & 0602 & $\mathrm{X}$ & $25.1(22.9-27.3)$ \\
\hline 10 & \multicolumn{2}{|c|}{$602 / 603 / 604^{\mathrm{b}}$} & $24.7(22.4-27.0)$ & 02 & $\mathrm{X}$ & $24.8(23.0-26.6)$ \\
\hline 11 & 0604 & $\mathrm{X}$ & $24.6(20.3-28.9)$ & 0602 & 0301 & $24.6(21.6-27.6)$ \\
\hline 12 & 0302 & $\mathrm{X}$ & $24.6(22.3-26.9)$ & 0602 & 02 & $24.5(21.8-27.2)$ \\
\hline 13 & 0603 & 02 & $24.4(20.6-28.2)$ & 0301 & 02 & $24.3(21.7-26.9)$ \\
\hline 14 & 0602 & 02 & $24.1(21.4-26.8)$ & 0301 & $\mathrm{X}$ & $24.2(22.1-26.3)$ \\
\hline 15 & 0602 & 0302 & $23.4(20.2-26.6)$ & 02 & 0604 & $24.2(19.7-28.7)$ \\
\hline 16 & 02 & 0302 & $22.9(20.1-25.7)$ & 0603 & 0301 & $23.9(19.4-28.4)$ \\
\hline 17 & 0603 & 0301 & $22.0(17.7-26.3)$ & $X$ & $X$ & $23.2(19.7-26.7)$ \\
\hline 18 & 02 & 0604 & $21.4(17.0-25.8)$ & 0602 & 0302 & $22.4(19.3-25.5)$ \\
\hline 19 & 0603 & 0302 & $20.0(15.8-24.2)$ & 0301 & 0302 & $21.9(18.9-24.9)$ \\
\hline
\end{tabular}

0603 included in their genotype were more likely to have a low frequency of LrBW.

Diabetes-risk HLA genotypes Children with DQB1*02 were typed for both DQA $1 * 0201$ and A1*0501 to specify the seven diabetes-risk HLA-genotype groups (Table 4). There was a strong association between the type 1 diabetes-risk genotypes and quartiles of $\mathrm{rBW}(p=0.01)$. Children with the diabetes high-risk HLA genotype DQB1* 0201-A1*0501/DQB1*0302-DQA1*0301 (DQ2/DQ8), genotype DQB1*0302/DQB1*0604 (DQ8/6.4) and DQ8/X had an increased frequency of HrBW (28.0\%)) compared to the rest of the population $(24.5 \%, p=0.0007)$ (odds ratio [OR] 1.20 [95\% CI 1.08-1.33], $p=0.0006)$. When compared to the neutral type 1 diabetes-HLA-risk group, children with DQ2/DQ8 had a significantly increased risk for $\mathrm{HrBW}$ (OR 1.32 [95\% CI 1.09-1.60], $p=0.004$ ) as well as children with DQ8/6.4 and DQ8/X (OR 1.21 [1.06-1.38], $p=0.005$ ). Children with low-risk HLA-DQB ${ }^{*} 0603$ were associated with increased frequency of HrBW (OR 1.13 [95\% CI 1.02-1.28], $p=0.025$ ) and decreased frequency of LrBW compared to neutrals (OR 0.88 [95\% CI 0.79-0.99], $p=0.03$ ). No other type 1 diabetes-HLA-risk group was associated with HrBW or LrBW.

Most of these data were confirmed when ultrasoundcorrected $Z$-scores were used. First, children with the diabetes high-risk HLA genotype DQB $1 * 0201-\mathrm{A} 1 * 0501$ / DQB1*0302-DQA1*0301 (DQ2/DQ8) had an increased frequency of $\mathrm{HrBW}$ (29.2\% compared to expected $25 \%$ ). This group differed significantly from all other genotype groups $(p=0.01)$. Second, when compared to the neutral type 1 diabetes HLA-risk group, children with DQ2/DQ8 had a significantly increased risk for $\mathrm{HrBW}$ (OR 1.30
[95\% CI 1.08-1.56], $p=0.006)$. The DQ8/0604 or DQ8/X were not significant. Children with low-risk HLA-DQB1* 0603 were associated with $\mathrm{HrBW}$ (OR of 1.12 [1.011.26], $p=0.039$ ) compared to neutrals. However, this association was due more to a strong protection from $\mathrm{LrBW}$ (OR $0.83[0.75-0.93], p=0.002$ ), as the frequency of HrBW among DQB $1 * 0603$-positive children did not differ from the frequency of children in the normal standard weight groups ( 2 nd and 3rd quartile).

GAD65 and IA-2 autoantibodies In all, 477 (3.0\%) term children had autoantibodies to GAD65 or IA-2. Of these, 413 had GAD65Ab, 14 had IA-2Ab and 50 had both. Only GAD65Ab were associated with relative birthweight. Children with antibodies to GAD65 were less likely to have HrBW (OR=0.78 [95\% CI 0.62-0.98], $p=0.03)$. This association remained significant after adjusting for confounding factors (Table 5).

\section{Discussion}

In this study we analysed a large group of newborn children from the Skåne province of Sweden to discover that children with the HLA-DQ2/DQ8 and DQ8/0604 and DQ8/X genotypes had a higher frequency of HrBW. We confirmed that children with the DQB $1 * 0603$ allele, strongly linked to DR13 [37] and known to be protective of type 1 diabetes, also had a higher frequency of HrBW. The data therefore confirm the previous correlation between DR13 and mean BW [27], but suggest that the effect could be from either the DQ or DR or from both alleles. The effects on BW were small and therefore not likely to be seen in study 
Table 4 Percent of different HLA type 1 diabetes genotypes and risk groups having a relative birthweight in the lower (LrBW), second, third and upper (HrBW) quartile of all term children $(n=16,055)$

\begin{tabular}{|c|c|c|c|c|c|c|c|}
\hline \multirow[t]{2}{*}{$\begin{array}{l}\text { Diabetes } \\
\text { risk }^{\mathrm{a}}\end{array}$} & \multicolumn{2}{|c|}{$\begin{array}{l}\text { HLA DQB1 } \\
\text { genotype }\end{array}$} & \multirow[b]{2}{*}{$n$} & \multicolumn{4}{|c|}{$\begin{array}{l}\text { Relative birthweight (percent } \\
\text { of genotype in each quartile) }\end{array}$} \\
\hline & Haplo 1 & Haplo 2 & & $1 \mathrm{st}$ & 2 nd & $3 \mathrm{rd}$ & 4 th \\
\hline \multicolumn{3}{|c|}{ All term children } & 16,055 & 25.0 & 25.0 & 25.0 & 25.0 \\
\hline \multicolumn{2}{|c|}{ Very high $02^{\mathrm{b}}$} & 0302 & 594 & $\begin{array}{l}22.6 \\
22.6^{\mathrm{c}}\end{array}$ & $\begin{array}{l}22.4^{\mathrm{c}} \\
22.4^{\mathrm{c}}\end{array}$ & $\begin{array}{l}25.7 \\
25.7^{\mathrm{c}}\end{array}$ & $\begin{array}{l}29.3 \\
29.3^{\mathrm{c}}\end{array}$ \\
\hline igh & 0302 & 0604 & 196 & 26 & & & 27.0 \\
\hline & 0 & $X$ & 8 & $\begin{array}{l}24.6 \\
24.8^{\mathrm{c}}\end{array}$ & $\begin{array}{l}24.1 \\
23.7^{\mathrm{c}}\end{array}$ & $\begin{array}{l}23.7 \\
24.0^{\mathrm{c}}\end{array}$ & $\begin{array}{l}27.6 \\
27.5^{\mathrm{c}}\end{array}$ \\
\hline Mod & $02^{\mathrm{b}}$ & 0604 & 221 & 18.6 & 24.9 & 30.3 & 26.2 \\
\hline Mo & $02^{\mathrm{b}}$ & $X$ & 1,121 & $\begin{array}{l}27.2 \\
25.8^{\mathrm{c}}\end{array}$ & $\begin{array}{l}25.4 \\
25.3^{\mathrm{c}}\end{array}$ & $\begin{array}{l}22.9 \\
24.1^{\mathrm{c}}\end{array}$ & $\begin{array}{l}24.5 \\
24.8^{\mathrm{c}}\end{array}$ \\
\hline Neutral & $02^{\mathrm{d}}$ & 0604 & 120 & 26.7 & 28.3 & 24.2 & 20.8 \\
\hline Neutral & $02^{\mathrm{d}}$ & $X$ & 611 & 26.4 & 2 & 2 & 26.2 \\
\hline Neutral & $02^{\mathrm{d}}$ & $02^{\mathrm{b}}$ & 411 & 23.1 & 28.0 & 25.5 & 23.4 \\
\hline Neutral & $02^{\mathrm{d}}$ & 0302 & 301 & 23.6 & 25.6 & 27.2 & 23.6 \\
\hline Neutral & 03 & 02 & 1,069 & 25.6 & & & 4.3 \\
\hline & 0 & 03 & & & & & 1.9 \\
\hline $\mathrm{Ne}$ & 060 & $\mathrm{X}$ & 82 & 24.6 & & 2 & 25.1 \\
\hline $\mathrm{Neu}$ & $\mathrm{X}$ & $\mathrm{X}$ & 574 & $\begin{array}{l}25.1 \\
25.9^{\mathrm{c}}\end{array}$ & & $\begin{array}{l}28.8 \\
25.2^{\mathrm{c}}\end{array}$ & $\begin{array}{l}23.2 \\
23.8^{\mathrm{c}}\end{array}$ \\
\hline LO & & 060 & 260 & 27.3 & 2 & 20.4 & 25.4 \\
\hline Low & 0301 & $\mathrm{X}$ & 1,672 & $\begin{array}{l}26.0 \\
26.1^{\mathrm{c}}\end{array}$ & $\begin{array}{l}26.7 \\
26.7^{\mathrm{c}}\end{array}$ & $\begin{array}{l}23.1 \\
22.8^{\mathrm{c}}\end{array}$ & $\begin{array}{l}24.2 \\
24.4^{\mathrm{c}}\end{array}$ \\
\hline & 0 & 03 & 6 & 20.0 & & & 28.3 \\
\hline Very low & 0603 & 02 & 500 & 24.4 & 0 & 25.0 & 26.6 \\
\hline Very low & 0603 & 0301 & 351 & 22.0 & 23.9 & 30.2 & 23.9 \\
\hline Very low & $0602 / 060$ & $03 / 0604^{\mathrm{e}}$ & 1337 & $\begin{array}{l}24.7 \\
23.6^{\mathrm{c}}\end{array}$ & $\begin{array}{l}24.4 \\
24.4^{\mathrm{c}}\end{array}$ & $\begin{array}{l}24.7 \\
25.7^{\mathrm{c}}\end{array}$ & $\begin{array}{l}26.2 \\
26.3^{\mathrm{c}}\end{array}$ \\
\hline IVO IISK & 0602 & 030 & 692 & 23.4 & 26.6 & 27.6 & 22.4 \\
\hline & 0602 & 02 & 960 & 24.1 & 24.7 & 26.8 & 24.5 \\
\hline No risk & 0602 & 0301 & 802 & 25.6 & 24.6 & 25.3 & 24.6 \\
\hline No & 0602 & $X$ & 495 & $\begin{array}{l}24.7 \\
24.7^{\mathrm{c}}\end{array}$ & $\begin{array}{l}24.8 \\
24.9^{\mathrm{c}}\end{array}$ & $\begin{array}{l}25.5 \\
26.3^{\mathrm{c}}\end{array}$ & $\begin{array}{l}25.1 \\
24.1^{\mathrm{c}}\end{array}$ \\
\hline
\end{tabular}

$\mathrm{X}$ is not DQB1 02, 0301, 0302, 0602, 0603, 0604 but includes potential homozygosity

${ }^{a}$ Inclusion criteria used to identify newborns most at risk of developing type 1 diabetes

${ }^{\mathrm{b}} \mathrm{DQB} 1 * 02-\mathrm{DQA} 1 * 0501$

${ }^{\mathrm{c}}$ Significant difference between diabetes-risk groups $(p=0.01)$ after overall chi square test

${ }^{\mathrm{d}} \mathrm{DQB} 1 * 02-\mathrm{DQA} 1 * 0201$

${ }^{\mathrm{e}}$ Genotypes DQB1* 0603/0602, 0603/0604, 0603/X or $0602 / 0604$

populations of a relatively little size. For example, in a previous study it was reported that the HLA-DQ2/DQ8 genotype had a lower BW compared to DQB1*0602/ DQB $1 * 0602$, but this conclusion was based on only 969 children [38].

The development of type 1 diabetes is thought to be a result of genetic susceptibility in combination with environmental factors. Numerous triggers for type 1 diabetes have been proposed. These include viral infections [39-41], dietary factors (cow's milk, nitrosamines, high protein intake) $[42,43]$, neonatal jaundice and $\mathrm{ABO}$ incompatibility [44], neonatal respiratory disease [44], early supplementary milk-based feeding, short time of breast-feeding [42, 45] and stress events such as severe life events [42, 46, 47]. Several studies have found that children who later develop diabetes have a higher BW than controls, and also have an increased linear growth in childhood [15, 16, 42, 48, 49]. Our finding that HLA genetic factors, which are associated with susceptibility for type 1 diabetes, are related to intrauterine growth might in fact contribute to the increased BW in type 1 diabetes children.

We also showed that other, non-diabetes-associated HLA genotypes, could be ranked in order according to frequency of children with HrBW and LrBW. The HLA types with the highest frequency of children with LrBW had a low frequency of children with HrBW and the opposite. The conclusion of this is that HLA genotypes seem to have a modulating effect on BW. This direct correlation between HLA-DQ subtypes and BW might explain the previously reported increase in $\mathrm{BW}$ in children who later develop type 1 diabetes. The mechanism may include different ways to respond to intrauterine infections, possibly by HLA-mediated alterations in the immune system. It could also represent an altered metabolic control in mothers with diabetes-susceptible genotypes, which perhaps give a subclinical hyperglycaemia during pregnancy and thus an increased BW. In the present study, all children born to mothers with diabetes and gestational diabetes were excluded, since these children are known to be heavier at birth. Children born to fathers with diabetes were not excluded, since this should not affect the BW. Further, we are not able to foresee if any of those fathers or mothers will get diabetes in the future.

There was a decrease in $\mathrm{rBW}$ with positive GAD65 autoantibodies in cord blood. This effect was independent of HLA and is of interest since it was recently report-

Table 5 Multiple logistic regression of HLA type 1 diabetes risk genotypes and autoantibodies on low and high relative birthweight, respectively

\begin{tabular}{llllll}
\hline & \multicolumn{2}{l}{ Low relative birthweight } & & High relative birthweight \\
\cline { 2 - 3 } \cline { 5 - 6 } Factor & OR $(95 \% \mathrm{CI})^{\mathrm{a}}$ & $p$ value & & OR $(95 \% \mathrm{CI})^{\mathrm{a}}$ & $p$ value \\
\hline HLA-T1DM-risk group & & & & \\
Very high risk & $0.83(0.67-1.02)$ & 0.072 & & $1.32(1.09-1.61)$ & 0.005 \\
High risk & $0.93(0.81-1.07)$ & 0.299 & & $1.23(1.07-1.41)$ & 0.003 \\
Moderate risk & $0.97(0.84-1.12)$ & 0.662 & & $1.10(0.95-1.27)$ & 0.198 \\
Low risk & $0.99(0.87-1.12)$ & 0.822 & & $1.04(0.92-1.19)$ & 0.527 \\
Very low & $0.88(0.78-0.98)$ & 0.026 & & $1.14(1.01-1.28)$ & 0.029 \\
No risk & $0.94(0.85-1.04)$ & 0.215 & & $1.01(0.91-1.12)$ & 0.895 \\
Autoantibodies & & & & & \\
GAD65Ab & $1.23(0.98-1.54)$ & 0.072 & & $0.72(0.56-0.93)$ & 0.010 \\
IA-2Ab & $1.10(0.62-1.94)$ & 0.738 & & $1.33(0.72-2.42)$ & 0.347 \\
\hline
\end{tabular}

T1DM, type 1 diabetes mellitus

${ }^{a}$ Results corrected in a multiple logistic regression for sex of child, maternal and gestational age, and number of cigarettes smoked daily by mother

${ }^{\mathrm{b}}$ The HLA reference group is neutral 
ed that offspring who were GAD or IA-2 autoantibody positive at birth had significantly lower risks for developing multiple islet autoantibodies and diabetes than offspring who were islet autoantibody negative at birth [50]. Further studies will therefore be needed to further analyse the possible effects of islet autoantibodies on BW since the number of children with autoantibodies in our study was small.

The cohort studied was representative of the entire population, but some differences between the mothers and children participating in DiPiS and those not participating were found. Older mothers were more likely to participate, whereas lower participation was evident when the child was born preterm. Our study contains a larger percentage of children born LGA $(5.0 \%)$, and a slightly lower percentage of children born SGA (1.7\%), than expected from the 1996 reference material $[33,34]$. Comparing this observation with a statistical report from the Swedish Medical Birth Registry, made by the National Board of Health and Welfare [51], confirmed that this was equivalent to a national trend of increasing BW and amount of children born LGA.

In conclusion, this large population of children born to healthy mothers showed an association between $\mathrm{HrBW}$ and the diabetes-high-risk HLA-DQ2/8, DQ8/0604, and $\mathrm{DQ} 8 / \mathrm{X}$, as well as the low-risk HLA-DQB $1 * 0603$. We speculate that previous observations of an association between high BW and type 1 diabetes are secondary to the primary association between HLA and BW, and that high BW may not be a risk factor for type 1 diabetes but an effect of HLA.

Acknowledgements Our research is supported in part by the Swedish Research Council (Grant 14064), Juvenile Diabetes Research Foundation/Wallenberg Foundation, Swedish Childhood Diabetes Foundation, Swedish Diabetes Association, Nordisk Insulin Fund, National Institutes of Health (DK26190, DK63861), UMAS funds, Terry \& Louise Gregg Diabetes in Pregnancy Award from the American Diabetes Foundation and the Skåne Council Foundation for Research and Development. We thank all the participating parents and children in DiPiS. The suggestions by one of the referees on ways of analysing the data were much appreciated.

Members of the DiPiS study group also include: B. BuverisSvendburg, A. Carlsson, E. Cederwall, C. Cilio, J. Gerardsson, B. Jönsson, P. Karimi, K. Kockum, K. Larsson, B. Lindberg, J. Neiderud, H. Rastkhani, P. Siming and S. Sjöblad.

\section{References}

1. Diabetes Epidemiology Research International Group (1990) Secular trends in incidence of childhood IDDM in 10 countries. Diabetes 39:858-864

2. Karvonen M, Tuomilehto J, Libman I et al (1993) A review of the recent epidemiological data on the worldwide incidence of type 1 (insulin-dependent) diabetes mellitus. World Health Organization DIAMOND Project Group. Diabetologia 36:883892

3. Dahlquist G, Mustonen L (1994) Childhood onset diabetestime trends and climatological factors. Int $\mathrm{J}$ Epidemiol 23: $1234-1241$
4. Gardner SG, Bingley PJ, Sawtell PA et al (1997) Rising incidence of insulin dependent diabetes in children aged under 5 years in the Oxford region: time trend analysis. The Bart'sOxford Study Group. BMJ 315:713-717

5. Svensson J, Carstensen B, Molbak A et al (2002) Increased risk of childhood type 1 diabetes in children born after 1985 . Diabetes Care 25:2197-2201

6. Tuomilehto J, Virtala E, Karvonen M et al (1995) Increase in incidence of insulin-dependent diabetes mellitus among children in Finland. Int J Epidemiol 24:984-992

7. EURODIAB Ace Study Group and EURODIAB Ace Substudy 2 Study Group (1998) Familial risk of type I diabetes in European children. Diabetologia 41:1151-1156

8. Todd JA (1995) Genetic analysis of type 1 diabetes using whole genome approaches. Proc Natl Acad Sci U S A 92:8560-8565

9. Redondo MJ, Fain PR, Eisenbarth GS (2001) Genetics of type 1A diabetes. Recent Prog Horm Res 56:69-89

10. Noble JA, Valdes AM, Cook M et al (1996) The role of HLA class II genes in insulin-dependent diabetes mellitus: molecular analysis of 180 Caucasian, multiplex families. Am J Hum Genet 59:1134-1148

11. Kockum I, Sanjeevi CB, Eastman S et al (1995) Population analysis of protection by HLA-DR and DQ genes from insulindependent diabetes mellitus in Swedish children with insulindependent diabetes and controls. Eur J Immunogenet 22:443465

12. Barnett AH, Eff C, Leslie RD et al (1981) Diabetes in identical twins. A study of 200 pairs. Diabetologia 20:87-93

13. Kaprio J, Tuomilehto J, Koskenvuo M et al (1992) Concordance for type 1 (insulin-dependent) and type 2 (non-insulindependent) diabetes mellitus in a population-based cohort of twins in Finland. Diabetologia 35:1060-1067

14. Patterson CC, Dahlquist G, Soltesz G et al (2001) Is childhoodonset type I diabetes a wealth-related disease? An ecological analysis of European incidence rates. Diabetologia 44 [Suppl 3]:B9-B16

15. Dahlquist G, Bennich SS, Kallen B (1996) Intrauterine growth pattern and risk of childhood onset insulin dependent (type I) diabetes: population based case-control study. BMJ 313:11741177

16. Stene LC, Magnus P, Lie RT et al (2001) Birth weight and childhood onset type 1 diabetes: population based cohort study. BMJ 322:889-892

17. Verge CF, Gianani R, Kawasaki E et al (1996) Prediction of type I diabetes in first-degree relatives using a combination of insulin, GAD, and ICA512bdc/IA-2 autoantibodies. Diabetes 45:926-933

18. Baekkeskov S, Aanstoot HJ, Christgau S et al (1990) Identification of the $64 \mathrm{~K}$ autoantigen in insulin-dependent diabetes as the GABA-synthesizing enzyme glutamic acid decarboxylase. Nature 347:151-156

19. Solimena M, Dirkx R Jr, Hermel JM et al (1996) ICA 512, an autoantigen of type I diabetes, is an intrinsic membrane protein of neurosecretory granules. EMBO J 15:2102-2114

20. Saeki K, Zhu M, Kubosaki A et al (2002) Targeted disruption of the protein tyrosine phosphatase-like molecule IA-2 results in alterations in glucose tolerance tests and insulin secretion. Diabetes 51:1842-1850

21. Atkinson MA, Eisenbarth GS (2001) Type 1 diabetes: new perspectives on disease pathogenesis and treatment. Lancet 358:221-229

22. Lindberg B, Ivarsson SA, Landin-Olsson M et al (1999) Islet autoantibodies in cord blood from children who developed type I (insulin-dependent) diabetes mellitus before 15 years of age. Diabetologia 42:181-187

23. Hypponen E, Virtanen SM, Kenward MG et al (2000) Obesity, increased linear growth, and risk of type 1 diabetes in children. Diabetes Care 23:1755-1760 
24. Baum JD, Ounsted M, Smith MA (1975) Letter: Weight gain in infancy and subsequent development of diabetes mellitus in childhood. Lancet 2:866

25. Johansson C, Samuelsson U, Ludvigsson J (1994) A high weight gain early in life is associated with an increased risk of type 1 (insulin-dependent) diabetes mellitus. Diabetologia 37: 91-94

26. Bruining GJ (2000) Association between infant growth before onset of juvenile type-1 diabetes and autoantibodies to IA-2. Netherlands Kolibrie study group of childhood diabetes. Lancet 356:655-656

27. Aroviita P, Partanen J, Sistonen P et al (2004) High birth weight is associated with human leukocyte antigen (HLA) DRB1*13 in full-term infants. Eur J Immunogenet 31:21-26

28. Sjoroos M, Iitia A, Ilonen J et al (1995) Triple-label hybridization assay for type-1 diabetes-related HLA alleles. Biotechniques 18:870-877

29. Ilonen J, Reijonen H, Herva E et al (1996) Rapid HLA-DQB1 genotyping for four alleles in the assessment of risk for IDDM in the Finnish population. The Childhood Diabetes in Finland (DiMe) Study Group. Diabetes Care 19:795-800

30. Hampe CS, Hammerle LP, Bekris L et al (2000) Recognition of glutamic acid decarboxylase (GAD) by autoantibodies from different GAD antibody-positive phenotypes. J Clin Endocrinol Metab 85:4671-4679

31. Grubin CE, Daniels T, Toivola B et al (1994) A novel radioligand binding assay to determine diagnostic accuracy of isoform-specific glutamic acid decarboxylase antibodies in childhood IDDM. Diabetologia 37:344-350

32. Verge CF, Stenger D, Bonifacio E et al (1998) Combined use of autoantibodies (IA-2 autoantibody, GAD autoantibody, insulin autoantibody, cytoplasmic islet cell antibodies) in type 1 diabetes: Combinatorial Islet Autoantibody Workshop. Diabetes 47:1857-1866

33. Marsal K, Persson PH, Larsen T et al (1996) Intrauterine growth curves based on ultrasonically estimated foetal weights. Acta Paediatr 85:843-848

34. Persson PH, Weldner BM (1986) Intra-uterine weight curves obtained by ultrasound. Acta Obstet Gynecol Scand 65:169173

35. Larsson K, Elding-Larsson H, Cederwall E et al (2004) Genetic and perinatal factors as risk for childhood type 1 diabetes. Diabetes Metab Res Rev 20:429-437

36. Lernmark B, Elding Larsson H, Hansson G et al (2004) Parent responses to participation in genetic screening for diabetes risk. Pediatr Diabetes 5:174-181

37. Hermann R, Turpeinen H, Laine AP et al (2003) HLA DR-DQencoded genetic determinants of childhood-onset type 1 diabetes in Finland: an analysis of 622 nuclear families. Tissue Antigens 62:162-169
38. Stene LC, Magnus P, Ronningen KS et al (2001) Diabetesassociated HLA-DQ genes and birth weight. Diabetes 50:28792882

39. Dahlquist G, Frisk G, Ivarsson SA et al (1995) Indications that maternal coxsackie $\mathrm{B}$ virus infection during pregnancy is a risk factor for childhood-onset IDDM. Diabetologia 38:1371-1373

40. Dahlquist GG, Ivarsson S, Lindberg B et al (1995) Maternal enteroviral infection during pregnancy as a risk factor for childhood IDDM. A population-based case-control study. Diabetes 44:408-413

41. Hyoty H, Hiltunen M, Knip M et al (1995) A prospective study of the role of coxsackie $\mathrm{B}$ and other enterovirus infections in the pathogenesis of IDDM. Childhood Diabetes in Finland (DiMe) Study Group. Diabetes 44:652-657

42. Dahlquist G, Blom L, Lonnberg G (1991) The Swedish Childhood Diabetes Study - a multivariate analysis of risk determinants for diabetes in different age groups. Diabetologia 34:757-762

43. Dahlquist GG, Blom LG, Persson LA et al (1990) Dietary factors and the risk of developing insulin dependent diabetes in childhood. BMJ 300:1302-1306

44. Dahlquist GG, Patterson C, Soltesz G (1999) Perinatal risk factors for childhood type 1 diabetes in Europe. The EURODIAB Substudy 2 Study Group. Diabetes Care 22:1698-1702

45. Virtanen SM, Rasanen L, Aro A et al (1992) Feeding in infancy and the risk of type 1 diabetes mellitus in Finnish children. The 'Childhood Diabetes in Finland' Study Group. Diabet Med 9:815-819

46. Thernlund GM, Dahlquist G, Hansson K et al (1995) Psychological stress and the onset of IDDM in children. Diabetes Care 18:1323-1329

47. Robinson N, Fuller JH (1985) Role of life events and difficulties in the onset of diabetes mellitus. J Psychosom Res 29: 583-591

48. Blom L, Persson LA, Dahlquist G (1992) A high linear growth is associated with an increased risk of childhood diabetes mellitus. Diabetologia 35:528-533

49. EURODIAB Substudy 2 Study Group (2002) Rapid early growth is associated with increased risk of childhood type 1 diabetes in various European populations. Diabetes Care 25: $1755-1760$

50. Koczwara K, Bonifacio E, Ziegler AG (2004) Transmission of maternal islet antibodies and risk of autoimmune diabetes in offspring of mothers with type 1 diabetes. Diabetes 53:1-4

51. National Board of Health and Welfare (2002) Fakta om mammor, förlossningar, nyfödda barn-Medicinska födelseregistret 1973-2000 